\title{
Correlation of elevated level of blood midkine with poor prognostic factors of human neuroblastomas
}

\author{
S Ikematsu',2, A Nakagawara ${ }^{3}$, Y Nakamura ${ }^{3}$, S Sakuma ${ }^{4}$, K Wakai $^{5}$, T Muramatsu' and K Kadomatsu,, $^{*}$ \\ 'Department of Biochemistry, Nagoya University Graduate School of Medicine, 65 Tsurumai-cho, Showaku, Nagoya 466-8550, Japan; ${ }^{2}$ Pharmaceuticals \\ Development Department, Meiji Dairies Co., Odawara 250-0862, Japan; ${ }^{3}$ Division of Biochemistry, Chiba Cancer Center Research Institute, Chiba \\ 260-87 I 7, Japan; ${ }^{4}$ Cell Signals Inc., Tokyo I 0 I-0035, Japan; ${ }^{5}$ Department of Preventive Medicine/Biostatistics and Medical Decision Making, \\ Nagoya University Graduate School of Medicine, Nagoya 466-8550, Japan
}

The heparin-binding growth factor midkine (MK) is the product of a retinoic acid-responsive gene, and is implicated in neuronal survival and differentiation, and carcinogenesis. We previously reported that MK mRNA expression is elevated in neuroblastoma specimens at all stages, whereas pleiotrophin, the other member of the MK family, is expressed at high levels in favourable neuroblastomas. As MK is a secretory protein, it can be detected in the blood. Here, we show a significant correlation of the plasma MK level with prognostic factors of neuroblastomas. The plasma MK level was determined in 220 patients with neuroblastomas, and compared with that in children without malignant tumors $\left(n=17,<500 \mathrm{pg} \mathrm{ml}^{-1}\right)$. The plasma MK level became significantly elevated with advancing stages (stage I: $445 \mathrm{pg} \mathrm{ml}^{-1}$ (median), $n=73$; stage 2: 589, $n=39$; stage 3: 864, $n=40 ;$ stage 4: I445, $n=56 ;$ and stage 4S: 2439, $n=12$ ). More importantly, a higher MK level was strongly correlated with poor prognostic factors: over I year of age $(P=0.0299)$, MYCN amplification $(P<0.0001)$, low TrkA expression $(P=0.0005)$, nonmass screening, sporadic neuroblastomas $(P<0.000 \mathrm{I})$, and diploidy/tetraploidy $(P=0.0007)$. Thus, these results demonstrate that the plasma MK level is a good marker for evaluating the progression of neuroblastomas. Moreover, considering the ability of antisense MK oligodeoxyribonucleotide to suppress tumour growth of colorectal carcinoma cells in nude mice, as recently reported, the present study suggests that MK is a possible candidate molecular target for therapy for neuroblastomas.

British Journal of Cancer (2003) 88, I522 - 1526. doi:I0.1038/sj.bjc.6600938 www.bjcancer.com

(c) 2003 Cancer Research UK

Keywords: growth factor; midkine; molecular target; neuroblastoma; tumour marker

Midkine $(\mathrm{MK})$ is a heparin-binding growth factor that was originally discovered as the product of a retinoic acid-responsive gene during the differentiation of embryonal carcinoma cells (Kadomatsu et al, 1988; Tomomura et al, 1990; Muramatsu, 2002). The MK family consists of only two members, namely MK and pleiotrophin (PTN; also called HB-GAM), and is distinct from other heparin-binding growth factor families (Kurtz et al, 1995; Rauvala et al, 2000; Deuel et al, 2002; Muramatsu, 2002). Regarding the biological roles of MK, at least three important issues should be pointed out. First, a pivotal role of MK in the migration of inflammatory cells has been revealed by studies involving MK knockout mice; MK-deficient mice are more resistant to vascular restenosis and nephritis induced by reperfusion (Horiba et al, 2000; Sato et al, 2001). Second, MK exhibits neuroprotective activity (Michikawa et al, 1993; Unoki et al, 1994; Owada et al, 1999), and enhances neurite extension (Muramatsu et al, 1993). Induction of $\mathrm{MK}$ expression has been detected in reactive astrocytes in ischaemic lesions in human and animal brains (Wang et al, 1998; Wada et al, 2002). MK is deposited at senile plaques and neurofibrillary tangles in Alzheimer's patients (Yasuhara et al, 1993). MK binds to $\mathrm{A} \beta$ and inhibits its cytotoxicity

*Correspondence: Dr K Kadomatsu;

E-mail: kkadoma@med.nagoya-u.ac.jp

Received 27 November 2002; accepted 25 February 2003
(Yu et al, 1998). Third, MK is involved in carcinogenesis. Its expression is induced as early as at the precancerous stages of human colorectal and prostate carcinomas (Konishi et al, 1999; Ye et al, 1999), increases with the stages of human carcinomas, and is significantly linked to the prognosis (O'Brien et al, 1996; Mishima et al, 1997). MK transforms NIH3T3 cells (Kadomatsu et al, 1997), enhances fibrinolysis (Kojima et al, 1995), and promotes cell growth (Muramatsu and Muramatsu, 1991; Muramatsu et al, 1993; Takei et al, 2001), cell survival (Qi et al, 2000), cell migration (Takada et al, 1997; Maeda et al, 1999; Horiba et al, 2000; Qi et al, 2001), and angiogenesis (Choudhuri et al, 1997). MK antisense oligodeoxyribonucleotide suppresses tumour progression in nude mice (Takei et al, 2001, 2002).

The neuroblastoma is the most common solid malignant tumour in children. However, the molecular mechanisms underlying its pathogenesis and progression remain unclear, although several molecules, such as MYCN, TrkA, and TrkB, that are linked to the prognosis have been revealed (Brodeur et al, 1984; Nakagawara et al, 1995). This is one of the reasons why satisfactorily efficient therapies have not been established yet. A possible approach regarding such therapies is to seek molecular targets in neuroblastomas. We previously reported that $M K$ mRNA expression is elevated in neuroblastoma specimens at all stages (Nakagawara et al, 1995). Interestingly, the other MK family member, PTN, is expressed at high levels in favourable neuroblastomas (Nakagawara et al, 1995). As MK is a secretory 
protein, the blood MK level could be a strong tool for monitoring the status of neuroblastomas. This paper demonstrates that an elevated plasma level of MK is indeed significantly correlated with poor prognostic factors. Our results also indicate that MK could be a candidate molecular target for therapy for neuroblastomas.

\section{MATERIALS AND METHODS}

\section{Enzyme-linked immunoassay for human MK}

An enzyme-linked immunoassay (EIA) for human MK was performed as described previously (Ikematsu et al, 2000). Briefly, human MK was produced using Pichia pastoris GS115 by transfection with a human $\mathrm{MK}$ expression vector, which was constructed into pHIL-D4 (Invitrogen, Carlsbad, California, USA). This yeast-produced human MK was used to immunise rabbits and chickens to raise antibodies. The rabbit anti-human $\mathrm{MK}$ antibody $\left(50 \mu \mathrm{l}\right.$ of $5.5 \mu \mathrm{g} \mathrm{ml}^{-1}$ in $50 \mathrm{~mm}$ Tris $\mathrm{HCl}(\mathrm{pH} 8.2), 0.15 \mathrm{M} \mathrm{NaCl}, 0.1 \%$ $\mathrm{NaN}_{3}$ ) was coated onto the wells of microtitre plates (Polysorp plates, Nunc, Rochester, New York, USA) for $20 \mathrm{~h}$ at room temperature. After washing with $0.05 \%$ Tween 20 in PBS, the wells were blocked with $300 \mu \mathrm{l}$ of $0.1 \%$ casein, $0.01 \%$ Microcide I (aMReSCO) in PBS for $20 \mathrm{~h}$ at $37^{\circ} \mathrm{C}$. Plasma samples $(10 \mu \mathrm{l} \mathrm{each})$ were mixed with $100 \mu$ l of $50 \mathrm{~mm}$ Tris $\mathrm{HCl}(\mathrm{pH} 8.4), 0.5 \mathrm{M} \mathrm{KCl}, 0.1 \%$ casein, $0.5 \%$ BSA, $0.01 \%$ Microcide I, and $0.1 \mu \mathrm{g} \mathrm{ml}^{-1}$ peroxidaselabelled chicken anti-human MK antibody. Aliquots of $50 \mu \mathrm{l}$ of this mixture were added to wells prepared as described above, and further subjected to chromogenic detection at $\mathrm{OD}_{450}$ using tetramethylbenzidine as the substrate. This EIA system shows linearity from 0 to $4 \mathrm{ng} \mathrm{ml}^{-1}$ of $\mathrm{MK}$, and there is no crossreaction with PTN (Ikematsu et al, 2000).

\section{Plasma samples}

Plasma samples were obtained from blood collected from outcome patients without malignant tumours $(n=17)$ and neuroblastoma patients $(n=220)$. The information is summarised in Table 1.

Table I Blood samples

\begin{tabular}{|c|c|}
\hline & $n$ \\
\hline No malignant tumours & 17 \\
\hline$<$ I year & | | \\
\hline$>1$ year & 6 \\
\hline Neuroblastomas & 220 \\
\hline Stage I & 73 \\
\hline Stage 2 & 39 \\
\hline Stage 3 & 40 \\
\hline Stage 4 & 56 \\
\hline Stage 4S & 12 \\
\hline MYCN amplification - & 176 \\
\hline MYCN amplification + & 21 \\
\hline High TrkA expression & 157 \\
\hline Low TrkA expression & 53 \\
\hline Mass screening & 122 \\
\hline Sporadic & 82 \\
\hline Hyperdiploidy/pentaploidy & 91 \\
\hline Diploidy/tetraploidy & 119 \\
\hline$<$ I year & 154 \\
\hline$>$ I year & 52 \\
\hline
\end{tabular}

Sum from each group number does not necessarily match the total number, because some information is missing for some individuals.

\section{Statistics}

For statistical analysis as to stages, the Kruskal-Wallis test was used to evaluate the statistical differences between groups. The Mann-Whitney $U$-test with Bonferroni's correction was used to further evaluate the difference between the two groups. For analysis as to other prognostic factors, the Mann-Whitney $U$-test was used. $P<0.05$ was taken to be statistically significant.

\section{RESULTS}

\section{The plasma MK level increases with advancing stages}

Plasma samples were collected from children without malignant tumours and neuroblastoma patients. The information on individuals and neuroblastomas is summarised in Table 1. Plasma from individuals without malignant tumours showed low levels of MK (116-483 $\mathrm{pg} \mathrm{ml}^{-1}$; median, 205) (Figure 1). These values are consistent with the data for sera from healthy adults (median, $154 \mathrm{pg} \mathrm{ml}^{-1}$; cutoff value, $500 \mathrm{pg} \mathrm{ml}^{-1}$ ) (Ikematsu et al, 2000). The EIA employed in the present study showed no difference between serum and plasma (data not shown). These results indicate that the plasma level of MK does not change with age, and that the cutoff value can be set as $500 \mathrm{pg} \mathrm{ml}^{-1}$ for children.

The plasma MK level increased with advancing neuroblastoma stages. The median values were 445, 589, 864, 1445, and $2439 \mathrm{pg} \mathrm{ml}^{-1}$ for stages $1,2,3,4$, and $4 \mathrm{~S}$, respectively (Figure 1). The percentages of patients showing MK levels of more than the cutoff value were $38.4,59.0,70.0,83.9$, and $91.7 \%$ for stages $1,2,3$, 4 , and $4 \mathrm{~S}$, respectively (Figure 1). The statistical significance is summarised in Table 2. Although stage $4 \mathrm{~S}$ is included in the favourable neuroblastomas along with stages 1 and 2, the MK level was the highest at stage $4 \mathrm{~S}$ among the stages. This may be interpreted as indicating that one of the parameters influencing the plasma MK level is the tumour volume.

\section{An elevated plasma MK level is correlated with poor prognostic factors of neuroblastomas}

The neuroblastoma is one of the best studied tumours. Several factors have been determined to be significantly linked to the prognosis. Cases with amplified MYCN show a poor prognosis (Brodeur et al, 1984). Low-level expression of the NGF receptor $\operatorname{Trk} A$ is linked to a poor prognosis (Nakagawara et al, 1993). Sporadic neuroblastomas show a worse outcome as compared with neuroblastomas detected by mass screening that is currently being carried out in Japan (Sawada, 1986). Neuroblastomas with diploidy or tetraploidy show a worse prognosis than those with hyperdiploidy or pentaploidy (Look et al, 1984). In addition, the outcome in patients of older than 1 year is worse compared with in patients of younger than 1 year (Fortner et al, 1968). All these prognostic factors were significantly correlated with a plasma MK level (Figure 2 and Table 3 ). A higher level of MK was correlated with MYCN amplification $(P<0.0001)$, low expression of TrkA $(P=0.0005)$, sporadic neuroblastomas $(P<0.0001)$, diploidy/tetraploidy $(P=0.0007)$, and older age $(P=0.0299)$.

\section{DISCUSSION}

This study demonstrated that the plasma MK level is significantly correlated with prognostic factors of human neuroblastomas. The only exception was that the plasma MK level was the highest at stage $4 \mathrm{~S}$ among the stages, although stage $4 \mathrm{~S}$ belongs to the favourable group of neuroblastomas. Stage $4 S$ is a special type of stage 4 . Tumours at stage $4 \mathrm{~S}$ show spontaneous regression (Evans et al, 1976). Before spontaneous regression, stage $4 \mathrm{~S}$ exhibits large tumours and metastasis to the liver, bone marrow, and skin. We 


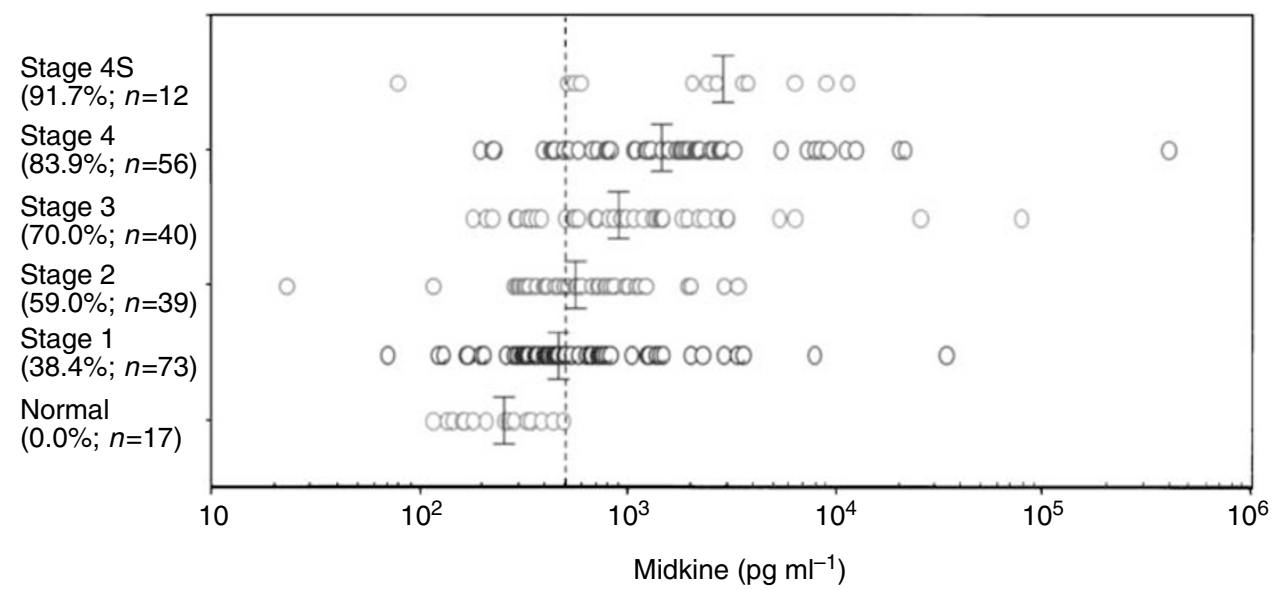

Figure I The plasma MK level becomes elevated with advancing neuroblastoma stages. The plasma MK level in children without malignant tumours was $205 \mathrm{pg} \mathrm{ml}^{-1}$ (median, $\left.n=17\right)$. Those at stages I, 2, 3, 4, and 4S were $445(n=73), 589(n=39), 864(n=40), \quad \mid 445(n=50)$, and $2439(n=12)$, respectively. The percentage of cases showing more than the cutoff value $\left(500 \mathrm{pg} \mathrm{ml}^{-1}\right)$ is shown in parentheses beneath each stage. The plasma MK level is significantly elevated at all neuroblastoma stages compared with the normal level. Statistical analysis is summarised in Table 2.

Table 2 Statistical analysis as to stages

\begin{tabular}{ccrccc}
\hline Stage & Normal & Stage I & Stage 2 & Stage 3 & Stage 4 \\
\hline 1 & $<0.001$ & & & & \\
2 & $<0.001$ & $0.5<$ & & & \\
3 & $<0.001$ & 0.039 & $0.5<$ & & \\
4 & $<0.001$ & $<0.001$ & $<0.001$ & $0.5<$ & \\
$4 \mathrm{~S}$ & 0.003 & 0.001 & 0.067 & $0.5<$ & $0.5<$ \\
\hline
\end{tabular}

The difference in serum MK level between the six groups was statistically significant $(P<0.000$ I, by the Kruskal - Wallis test). $P$-values in this table for differences between the two groups were derived from the Mann-Whitney U-test with Bonferroni's correction.

previously reported that MK mRNA expression in tumour specimens is very high at all human neuroblastoma stages, including stage $4 \mathrm{~S}$, as compared with that in benign tumours, that is, ganglioneuromas (Nakagawara et al, 1995). The present data for plasma MK are, therefore, consistent with our previous data for mRNA expression in tumours. Taken together, the results for stage $4 \mathrm{~S}$ suggest that the tumour volume is one of the factors that influence the plasma MK level. However, the tumour volume may not be the only factor that controls the plasma MK level, because we detected many cases that showed a high MK level even at stage 1 (Figure 1). In favourable neuroblastomas, for example, no MYCN amplification was discovered by mass screening, and we often observed high MK plasma levels. It should be noted that, even in favourable neuroblastomas, many cases exhibit poor clinical courses. We can expect that such cases can be evaluated and managed by means of monitoring the plasma level of MK. The importance of the present study is that it provided a chance to follow up prognosis of the patients with several parameters, including the plasma MK level. This perspective study is currently being carried out by our group, which will reveal the biological and clinical significance of an elevated plasma level of MK.

The present results also indicated that MK could be a candidate molecular target for therapy for neuroblastomas, because an elevated plasma MK level is linked with a poor prognosis. Cancerrelated activities of MK have been reported by many laboratories. These activities include transforming, migrating, fibrinolytic, mitogenic, antiapoptotic, and angiogenic ones (Kojima et al, 1995; Choudhuri et al, 1997; Kadomatsu et al, 1997; Qi et al, 2000, 2001). Furthermore, we recently succeeded in suppressing tumour growth by using antisense MK oligodeoxyribonucleotide (Takei

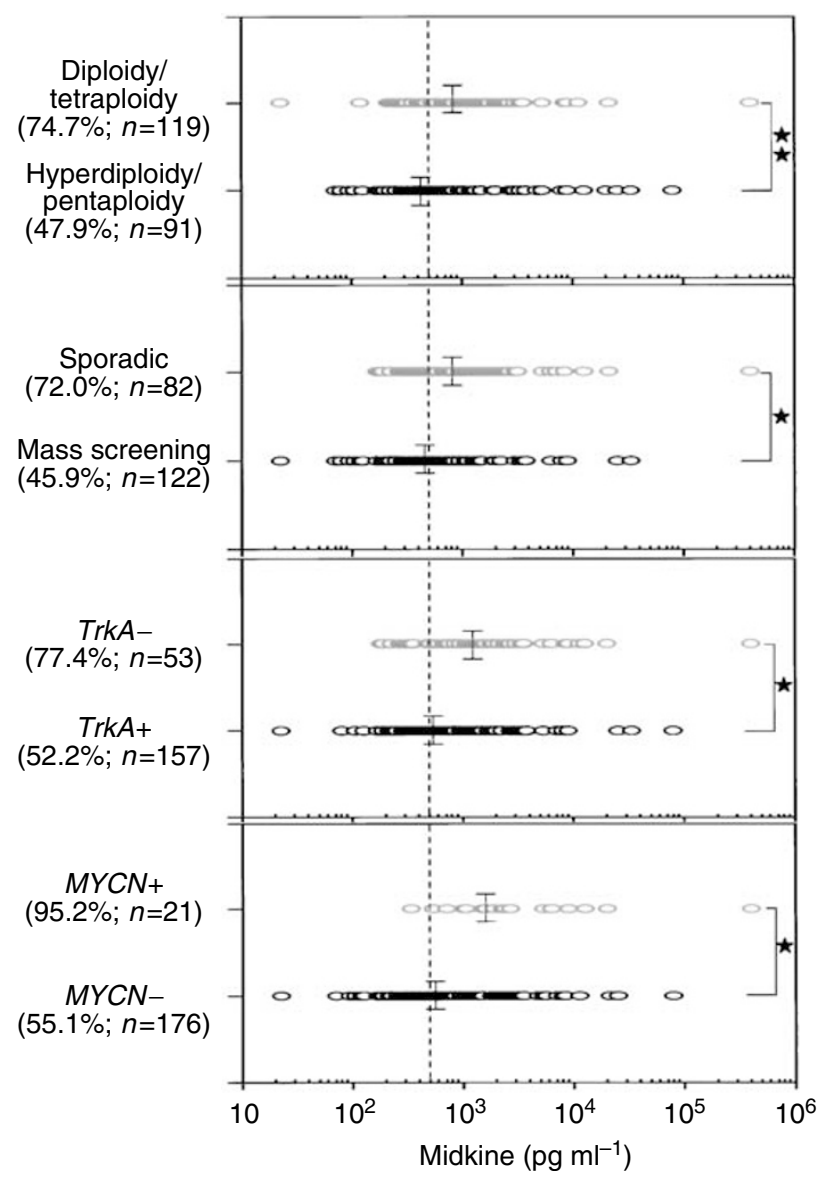

Figure 2 Correlation of the plasma MK level with several prognostic factors of neuroblastomas. Single asterisk, $P=0.0005$ or less; double asterisk, $P=0.0007$. The percentage of cases showing more than the cutoff value $\left(500 \mathrm{pg} \mathrm{ml}^{-1}\right)$ is shown in parentheses. Statistical analysis is summarised in Table 3.

et al, 2001, 2002). Thus, ablation of MK production or disruption of its signalling pathway could be a strong means of curing neuroblastomas. Regarding the signalling pathway of MK, receptor-type protein tyrosine phosphatase $\zeta$, anaplastic leukaemia 
Table 3 Statistical analysis as to several prognostic factors

\begin{tabular}{lr}
\hline MYCN amplification + vs - & $<0.0001$ \\
TrkA expression low vs high & 0.0005 \\
Sporadic vs mass screening & $<0.000$ I \\
Diploidy/tetraploidy vs hyperdiploidy/pentaploidy & 0.0007 \\
I year < vs I year $>$ & 0.0299 \\
\hline
\end{tabular}

Statistical analysis was performed using the Mann-Whitney U-test.

kinase, and LDL receptor-related protein (LRP) were recently identified as MK receptors (Maeda et al, 1999; Muramatsu et al, 2000; Stoica et al, 2002). Although it has not been elucidated yet whether or not these receptors form complexes for MK signalling, each protein serves as a receptor transducing intracellular signals for midkine. Further investigation of the MK action mechanism should provide insights as to a therapeutic strategy against aggressive neuroblastomas.

A recent report that 13-cis-retinoic acid could be a curative reagent for neuroblastomas (Matthay et al, 1999) prompted us to examine the effect of this reagent on MK production, because MK overproduction should make the prognosis worse if 13-cis-retinoic acid induced MK production. All-trans-retinoic acid as well as 13-cis-retinoic acid induced the intracellular production of $\mathrm{MK}$, but did not enhance the secretion of MK, probably because of premature binding, as described below (manuscript in preparation). The endocytosis of MK is completely dependent on LRP, and initiates nuclear targeting by MK, which is partly needed for the antiapoptotic activity of MK (Shibata et al, 2002). In addition, LRP functions as a biosynthesis regulator for MK. Overexpression of MK leads to premature binding and aggregation of MK and LRP in the endoplasmic reticulum during the biosynthesis of both proteins, thus preventing $\mathrm{MK}$ overproduction that might cause overgrowth or transformation of cells (manuscript in preparation). Taken together, the present results suggest that MK production during tumour development needs enhancing mechanisms at least at two steps: mRNA expression and protein secretion.

One of the characteristics of $M K$ expression is that it is frequently and highly expressed in malignant tumours regardless of the tissue type. This phenomenon is reminiscent of mutations in the p53 gene. We previously reported that an elevated serum MK level was detected in more than $80 \%$ frequency of human adult carcinomas (Ikematsu et al, 2000). Thus, monitoring of the level of the blood MK is applicable not only to neuroblastomas but also to adult carcinomas. Further assessment of the blood MK level with regard to tumour stages and prognosis of adult malignancy will provide indications for the use of blood $\mathrm{MK}$ as a tumour marker for each disease.

\section{ACKNOWLEDGEMENTS}

This work was supported by Grants-in-Aid from the Ministry of Education, Science, Sports, and Culture of Japan, and Grants-inAid for Center of Excellence Research.

\section{REFERENCES}

Brodeur GM, Seeger RC, Schwab M, Varmus HE, Bishop JM (1984) Amplification of $\mathrm{N}$-myc in untreated human neuroblastomas correlates with advanced disease stage. Science 224: $1121-1124$

Choudhuri R, Zhang HT, Donnini S, Ziche M, Bicknell R (1997) An angiogenic role for the neurokines midkine and pleiotrophin in tumorigenesis. Cancer Res 57: $1814-1819$

Deuel TF, Zhang N, Yeh HJ, Silos-Santiago I, Wang ZY (2002) Pleiotrophin: a cytokine with diverse functions and a novel signaling pathway. Arch Biochem Biophys 397: 162-171

Evans AE, Gerson J, Schnaufer L (1976) Spontaneous regression of neuroblastoma. Natl Cancer Inst Monogr 44: 49-54

Fortner J, Nicastri A, Murphy ML (1968) Neuroblastoma: natural history and results of treating 133 cases. Ann Surg 167: $132-142$

Horiba M, Kadomatsu K, Nakamura E, Muramatsu H, Ikematsu S, Sakuma S, Hayashi K, Yuzawa Y, Matsuo S, Kuzuya M, Kaname T, Hirai M, Saito H, Muramatsu T (2000) Neointima formation in a restenosis model is suppressed in midkine-deficient mice. J Clin Invest 105: $489-495$

Ikematsu S, Yano A, Aridome K, Kikuchi M, Kumai H, Nagano H, Okamoto K, Oda M, Sakuma S, Aikou T, Muramatsu H, Kadomatsu K, Muramatsu $\mathrm{T}$ (2000) Serum midkine levels are increased in patients with various types of carcinomas. Br J Cancer 83: $701-706$

Kadomatsu K, Hagihara M, Akhter S, Fan QW, Muramatsu H, Muramatsu $\mathrm{T}$ (1997) Midkine induces the transformation of NIH3T3 cells. Br J Cancer 75: $354-359$

Kadomatsu K, Tomomura M, Muramatsu T (1988) cDNA cloning and sequencing of a new gene intensely expressed in early differentiation stages of embryonal carcinoma cells and in mid-gestation period of mouse embryogenesis. Biochem Biophys Res Commun 151: 1312-1318

Kojima S, Muramatsu H, Amanuma H, Muramatsu T (1995) Midkine enhances fibrinolytic activity of bovine endothelial cells. J Biol Chem 270: $9590-9596$

Konishi N, Nakamura M, Nakaoka S, Hiasa Y, Cho M, Uemura H, Hirao Y, Muramatsu T, Kadomatsu K (1999) Immunohistochemical analysis of midkine expression in human prostate carcinoma. Oncology 57: $253-257$

Kurtz A, Schulte AM, Wellstein A (1995) Pleiotrophin and midkine in normal development and tumor biology. Crit Rev Oncog 6: 151-177
Look AT, Hayes FA, Nitschke R, McWilliams NB, Green AA (1984) Cellular DNA content as a predictor of response to chemotherapy in infants with unresectable neuroblastoma. $N$ Engl J Med 311: 231 - 235

Maeda N, Ichihara-Tanaka K, Kimura T, Kadomatsu K, Muramatsu T, Noda M (1999) A receptor-like protein-tyrosine phosphatase PTP $\zeta /$ RPTP $\beta$ binds a heparin-binding growth factor midkine. Involvement of arginine 78 of midkine in the high affinity binding to PTP $\zeta$. J Biol Chem 274: $12474-12479$

Matthay KK, Villablanca JG, Seeger RC, Stram DO, Harris RE, Ramsay NK, Swift P, Shimada H, Black CT, Brodeur GM, Gerbing RB, Reynolds CP (1999) Treatment of high-risk neuroblastoma with intensive chemotherapy, radiotherapy, autologous bone marrow transplantation, and 13-cisretinoic acid. Children's Cancer Group. N Engl J Med 341: 1165-1173

Michikawa M, Kikuchi S, Muramatsu H, Muramatsu T, Kim SU (1993) Retinoic acid responsive gene product, midkine, has neurotrophic functions for mouse spinal cord and dorsal root ganglion neurons in culture. J Neurosci Res 35: 530-539

Mishima K, Asai A, Kadomatsu K, Ino Y, Nomura K, Narita Y, Muramatsu $\mathrm{T}$, Kirino $\mathrm{T}$ (1997) Increased expression of midkine during the progression of human astrocytomas. Neurosci Lett 233: 29-32

Muramatsu H, Muramatsu T (1991) Purification of recombinant midkine and examination of its biological activities: functional comparison of new heparin binding factors. Biochem Biophys Res Commun 177: $652-658$

Muramatsu H, Shirahama H, Yonezawa S, Maruta H, Muramatsu T (1993) Midkine, a retinoic acid-inducible growth/differentiation factor: immunochemical evidence for the function and distribution. Dev Biol 159: $392-402$

Muramatsu H, Zou K, Sakaguchi N, Ikematsu S, Sakuma S, Muramatsu T (2000) LDL receptor-related protein as a component of the midkine receptor. Biochem Biophys Res Commun 270: 936-941

Muramatsu T (2002) Midkine and pleiotrophin: two related proteins involved in development, survival, inflammation and tumorigenesis. J Biochem 132: 359-371

Nakagawara A, Arima-Nakagawara M, Scavarda NJ, Azar CG, Cantor AB, Brodeur GM (1993) Association between high levels of expression of the TRK gene and favorable outcome in human neuroblastoma. $N$ Engl J Med 328: $847-854$ 
Nakagawara A, Milbrandt J, Muramatsu T, Deuel TF, Zhao H, Cnaan A, Brodeur GM (1995) Differential expression of pleiotrophin and midkine in advanced neuroblastomas. Cancer Res 55: $1792-1797$

O'Brien T, Cranston D, Fuggle S, Bicknell R, Harris AL (1996) The angiogenic factor midkine is expressed in bladder cancer, and overexpression correlates with a poor outcome in patients with invasive cancers. Cancer Res 56: 2515-2518

Owada K, Sanjo N, Kobayashi T, Mizusawa H, Muramatsu H, Muramatsu T, Michikawa M (1999) Midkine inhibits caspase-dependent apoptosis via the activation of mitogen-activated protein kinase and phosphatidylinositol 3-kinase in cultured neurons. J Neurochem 73: 2084-2092

Qi M, Ikematsu S, Ichihara-Tanaka K, Sakuma S, Muramatsu T, Kadomatsu K (2000) Midkine rescues Wilms' tumor cells from cisplatin-induced apoptosis: regulation of bcl-2 expression by midkine. J Biochem 127: $269-277$

Qi M, Ikematsu S, Maeda N, Ichihara-Tanaka K, Sakuma S, Noda M, Muramatsu T, Kadomatsu K (2001) Haptotactic migration induced by midkine. Involvement of protein-tyrosine phosphatase $\zeta$. Mitogenactivated protein kinase, and phosphatidylinositol 3-kinase. J Biol Chem 276: $15868-15875$

Rauvala H, Huttunen HJ, Fages C, Kaksonen M, Kinnunen T, Imai S, Raulo E, Kilpelainen I (2000) Heparin-binding proteins HB-GAM (pleiotrophin) and amphoterin in the regulation of cell motility. Matrix Biol 19: $377-387$

Sato W, Kadomatsu K, Yuzawa Y, Muramatsu H, Hotta N, Matsuo S, Muramatsu T (2001) Midkine is involved in neutrophil infiltration into the tubulointerstitium in ischemic renal injury. J Immunol 167: $3463-$ 3469

Sawada T (1986) Outcome of 25 neuroblastomas revealed by mass screening in Japan. Lancet 1: 377

Shibata Y, Muramatsu T, Hirai M, Inui T, Kimura T, Saito H, McCormick LM, Bu G, Kadomatsu K (2002) Nuclear targeting by the growth factor midkine. Mol Cell Biol 22: 6788-6696

Stoica GE, Kuo A, Powers C, Bowden ET, Sale EB, Riegel AT, Wellstein A (2002) Midkine binds to anaplastic lymphoma kinase (ALK) and acts as a growth factor for different cell types. J Biol Chem 277: 35990-35998
Takada T, Toriyama K, Muramatsu H, Song XJ, Torii S, Muramatsu T (1997) Midkine, a retinoic acid-inducible heparin-binding cytokine, in inflammatory responses: chemotactic activity to neutrophils and association with inflammatory synovitis. J Biochem 122: $453-458$

Takei Y, Kadomatsu K, Itoh H, Sato W, Nakazawa K, Kubota S, Muramatsu $\mathrm{T}$ (2002) 5'-, $3^{\prime}$-inverted thymidine-modified antisense oligodeoxynucleotide targeting midkine. Its design and application for cancer therapy. J Biol Chem 277: 23800-23806

Takei Y, Kadomatsu K, Matsuo S, Itoh H, Nakazawa K, Kubota S, Muramatsu T (2001) Antisense oligodeoxynucleotide targeted to Midkine, a heparin-binding growth factor, suppresses tumorigenicity of mouse rectal carcinoma cells. Cancer Res 61: 8486-8491

Tomomura M, Kadomatsu K, Matsubara S, Muramatsu T (1990) A retinoic acid-responsive gene, $\mathrm{MK}$, found in the teratocarcinoma system. Heterogeneity of the transcript and the nature of the translation product. J Biol Chem 265: $10765-10770$

Unoki K, Ohba N, Arimura H, Muramatsu H, Muramatsu T (1994) Rescue of photoreceptors from the damaging effects of constant light by midkine, a retinoic acid responsive gene product. Invest Opthalmol Vis Sci 35: $4063-4068$

Wada M, Kamata M, Aizu Y, Morita T, Hu J, Oyanagi K (2002) Alteration of midkine expression in the ischemic brain of humans. J Neurol Sci 200: $67-73$

Wang S, Yoshida Y, Goto M, Moritoyo T, Tsutsui J, Izumo S, Sato E, Muramatsu T, Osam M (1998) Midkine exists in astrocytes in the early stage of cerebral infarction. Brain Res Dev Brain Res 106: 205-209

Yasuhara O, Muramatsu H, Kim SU, Muramatsu T, Maruta H, McGeer PL (1993) Midkine, a novel neurotrophic factor, is present in senile plaques of Alzheimer disease. Biochem Biophys Res Commun 192: 246-251

Ye C, Qi M, Fan QW, Ito K, Akiyama S, Kasai Y, Matsuyama M, Muramatsu T, Kadomatsu K (1999) Expression of midkine in the early stage of carcinogenesis in human colorectal cancer. Br J Cancer 79: $179-184$

Yu GSP, Hu J, Nakagawa H (1998) Inhibition of $\beta$-amyloid cytotoxicity by midkine. Neurosci Lett 254: 125-128 